\title{
Approach to Accumulating History from Carboniferous Oil Cracking in East of Sichuan Basin
}

\author{
Guo jianming ${ }^{1, ~ a ~}$, Li Yanxia ${ }^{2, b}$ \\ ${ }^{1}$ School of Petroleum Engineering of Xi'an Shiyou University,Shaanxi xi'an,China \\ ${ }^{2}$ Shool of Earth Sciences \& Engineering of Xi'an Shiyou University,Shaanxi xi'an,China \\ ajmguo@xsyu.edu.cn, blyx4164@xsyu.edu.cn
}

Key words: East of Sichuan Basin; fluid inclusions; solid bitumen; efficiency of oil cracking

Abstract: Based on some characteristics of Carboniferous gas reservoir in eastern basin, such as the reservoir fluid inclusions, solid bitumen and so on, it is found that the gas reservoirs present a high content of methane (97\%), a great quantity of solid bitumen in the Carboniferous reservoir, fluid inclusions trapped at the high temperature $\left(180-220^{\circ} \mathrm{C}\right)$, multiphase (gas phase, solid phase and three-phase) inclusion and the changes of inclusion composition. All the factors above illustrate that the gas reservoir is oil-cracking gas.

\section{Introduction}

Similar to the kerogen pyrolysed hydrocarbon process, the thermally altered action(cracking) of crude oil in the oil reservoir is essentially a pyrolysis reaction at certain temperature, with the generation of gaseous hydrocarbon and residues (solid asphalt). Therefore, the reaction complies with the law of the chemical kinetics. It means that the cracking process of crude oil can be described by the equations of chemical kinetic. Recent years many scholars at home and abroad have carried out the study of the reaction of pyrolysis crude oil using chemical kinetics and hermal history to quantitatively evaluate the degree of cracking of crude oil[1-7].

In the eastern Sichuan Basin the Lower Paleozoic Silurian source rock has reached high to overmature stage, and vitrinite reflectance ( Ro ) reached more than $2 \%$ at present, with the distribution of $3.0-3.5 \%$ for majority of them, which illustrates that the hydrocarbon potential has been exhausted. However, a large number of gas reservoirs have been found in its overlying Carboniferous carbonate reservoir. Among the compositions in addition to the high concentration of methane (95.5 - 98\%) in the gas reservoir, the surplus are in large quantities of solid carbon bitumen that remain in the carbonate reservoir.

The paper is based on types of inclusions, homogenization temperature, composition, phase and solid asphalt, etc., to look for the evidence of thermal cracking of crude oil. All the above are necessary to reconstruct the process that the paleo-oil reservoir cracked into gas reservoir.

\section{Geological background}

In Sichuan Basin, as a major land-and-sea superimposed basin, there are multiple sets of source rock, multiple reservoir layers, changeable combination of reservoir and seal, multi-phase hydrocarbon generation, migration and accumulation process. In addition, Carboniferous gas reservoir is a relatively independent reservoir system which has its own source rock and reservoir layer. It is found that Chuandong Carboniferous gas reservoir is mainly from its underlying Silurian 
Longmaxi formation through comparison of gas source; And the layer is the initial hydrocarbon source kitchen of Carboniferous reservoir.

Longmaxi formation is composed of black shale, dark gray mudstone and calcareous shale of deep water continental shelf facies, which is an anaerobic and reduction deposition. A few drillings reveal that the thickness of Longmaxi formation is about 300-672m in Chuandong area. The average thickness of graptolite shale facies of hydrocarbon source rock is about $400 \mathrm{~m}$ in the lower part, varied between $100-900 \mathrm{~m}$, and the thickness of high-quality hydrocarbon source rock of the black shale changes between $20-70 \mathrm{~m}$. More over, the content of organic carbon is high to $0.5-7.5 \%$ in outcrop section. And the drillings reveal that the content of organic carbon is $0.07-2.77 \%$ (Well Wuke - 1), which shows that it is a good set of source rocks, this is the main source of the overlying Carboniferous gas.

\section{Characteristic of Fluid Inclusions}

Inorganic brine inclusions. Inorganic brine water inclusions take up great quantity of $10-25 \%$ (Fig. 1), which are trapped homogeneously, occurring in calcite veins, calcite, and gypsum and quartz infill. They appear as string of beads along the zone of the calcite crystal or cleavage cracks . They show the shapes of quadrilateral, square, diamond, elongate-shape, circle, ellipse and irregular. They are individually small $(5-10 \mu \mathrm{m})$, with the ratio of gas-liquid $5-10 \%$. The vapour phase is $\mathrm{CO} 2$. Generally, they are colorless-light brown under transmission light, but they don't have fluoresced under UV light. They are homogenous liquid when heated.

Organic inclusions. The organic inclusions can be further divided into hydrocarbon-bearing brine inclusions(vapour+liquid hydrocarbon+brine), liquid hydrocarbon inclusions, monophase vapour inclusions, monophase solid inclusions and three-phase inclusions(vapour+liquid+solid).

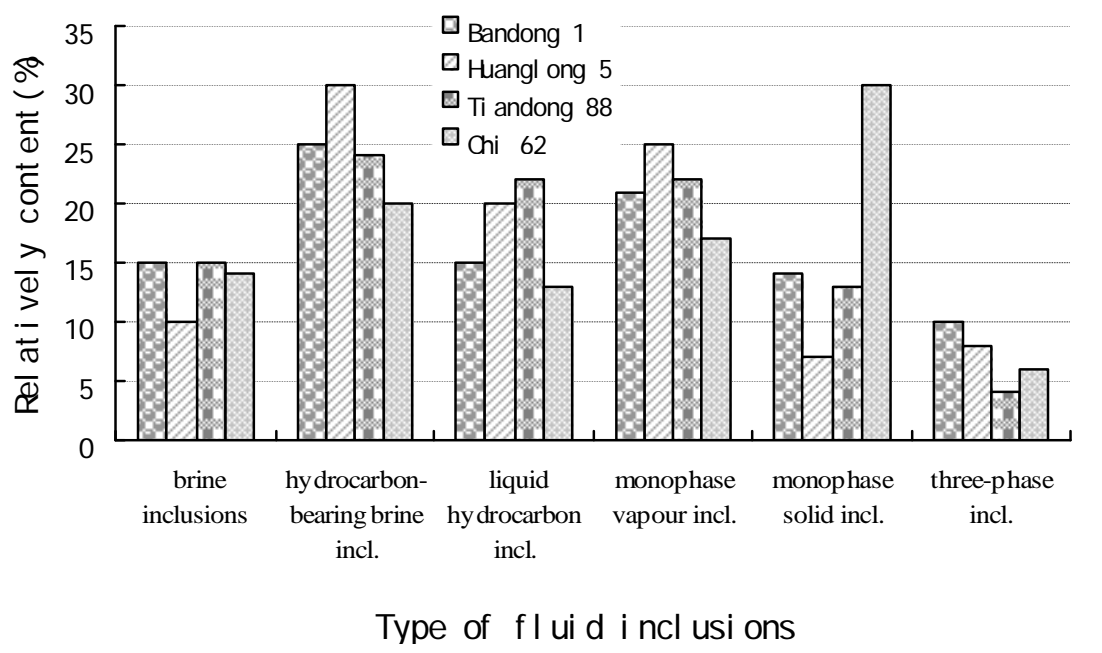

Figure 1 Type distribution of fluid inclusions for $C_{2}$ reservoir of east of Sichuan Basin

Filling periods petroleum. Generally, four periods of inclusions which developed in the cracks calcite veins of powder-crystalline dolomite and limestone $\left(\mathrm{C}_{2} \mathrm{hl}\right)$ can be seen (Fig. 2). I. Homogenization temperature range of brine inclusions is $100-135^{\circ} \mathrm{C}$; II. Homogenization temperature range of brine inclusions that associate with hydrocarbon-bearing saline inclusions is $140-180^{\circ} \mathrm{C}$, and the inclusions show blue white fluorescence; $\mathrm{III}_{1}$. Homogenization temperature range of brine inclusions that associate with hydrocarbon-bearing brine inclusions is $185-200^{\circ} \mathrm{C}$, and the inclusions show weak blue and white fluorescence; $\mathrm{III}_{2}$. Homogenization temperature range of brine inclusions that associate with hydrocarbon-bearing brine inclusions is $200-220^{\circ} \mathrm{C}$, without 
fluorescence; IV. Homogenization temperature range of brine inclusions that associate with hydrocarbon-bearing brine inclusions is $140-180^{\circ} \mathrm{C}$, without fluorescence. And it is difficult to distinguish the inclusions from the phase II by the temperature. The phase IV formed as the fluid filled after the tectonic uplift and erosion of Himalayan movement, which could be confirmed by the fluorescent color and composition analysis. The phase III particularly developed, which was the foremost filling stage, while Phase II and IV were also developed as the main filling stage.

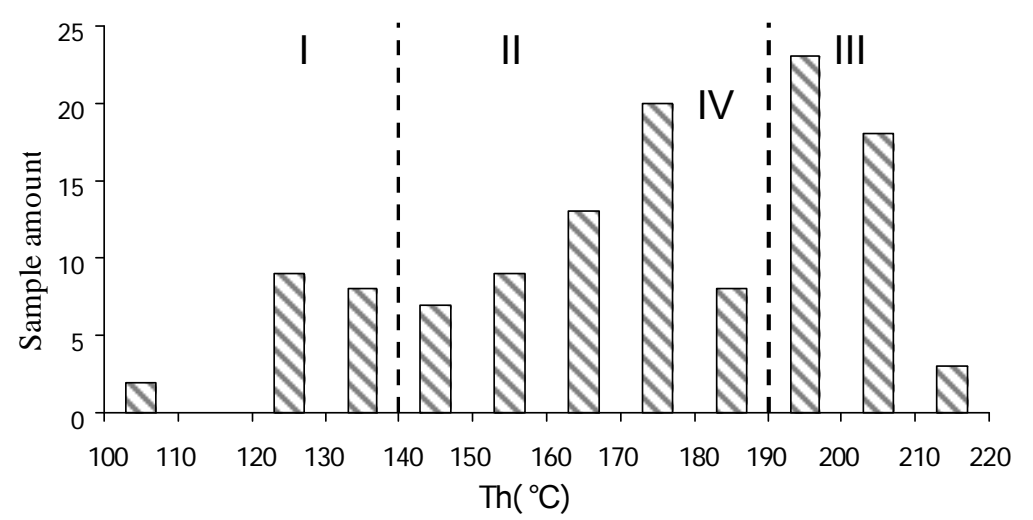

Fig. 2 Homogenization temperature distribution of fluid inclusions for $\mathrm{C}_{2}$ reservoir

Analysis of accumulation history. Wubaiti gas field is the largest gas field according to the proven reserves among the groups of Carboniferous gas fields in East Sichuan. Wubaiti gas field experienced four periods of hydrocarbon filling totally before Himalayan movement according to the burial history and the filling periods of hydrocarbon of the Wuke-1 well in Wubaiti gas field on Fig. 3, the fluorescent color and Homogenization temperature of fluid inclusions.

Accumulating period StageI: $205-185 \mathrm{Ma}$, the late Triassic and early Jurassic, oils formed through source kitchen of kerogen in the Lower Silurian, which migrated upward into the Middle Carboniferous reservoir to form the ancient oil reservoir. Accumulating period StageI: 165 -130Ma, Middle Jurassic-Early Cretaceous, oils and gases generated from late kerogen pyrolysis, continued to charge into the Middle Carboniferous reservoir to form ancient oil and gas reservoir; Accumulating period StageIII: 65 - 38Ma, Early Tertiary Paleocene epoch-the early Oligocene, the ancient gas reservoir cracked by the existing ancient oil and gas reservoir.

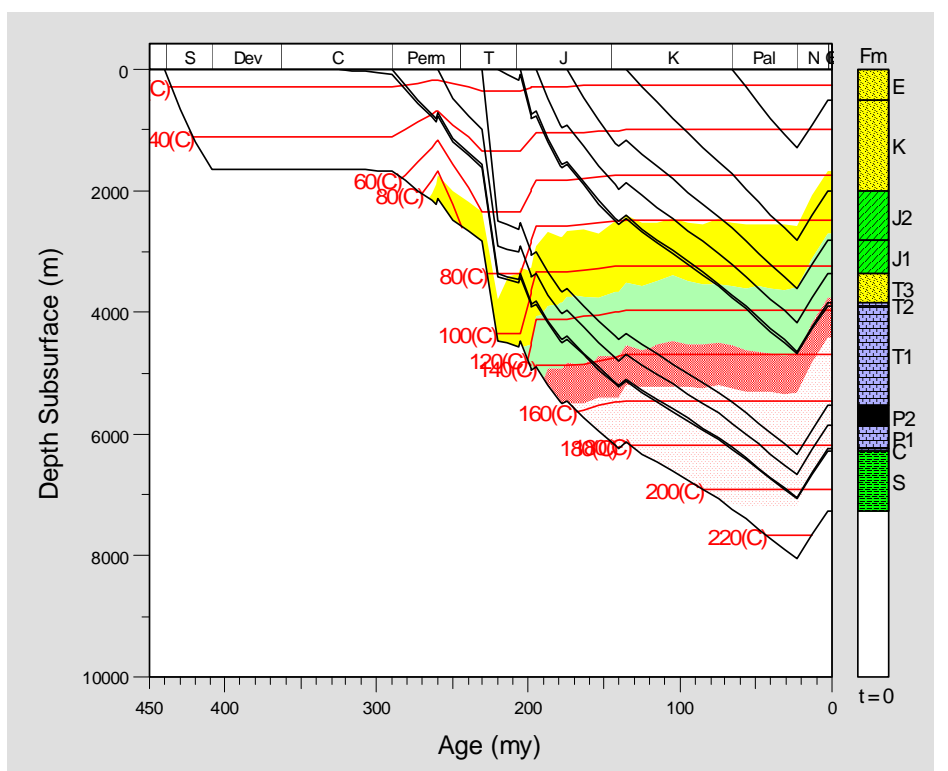

Fig. 3 Burial histories of Wuke 1 well of east of Sichuan Basin 
The eastern Sichuan basin suffered a strong compression and erosion during Himalayan movement at the end of Tertiary; and the ancient giant Carboniferous gas reservoirs in the Kaijiang paleo-uplift were split, collapsed and suffered a serious loss. As a local uplift within the scope of ancient gas reservoirs, Wubaiti buried structure could firstly trap the gas migrated from the ancient gas reservoir. Finally, the traps got high filling degree and accumulated once again, which was in the stage IV of period of accumulation during the period 23.3 - 0Ma, between late Tertiary Quaternary.

\section{Conclusions}

In Lower Silurian Longmaxi Formation the high efficient hydrocarbon source rocks has come to high to over-mature(VRo as high as $2.5-3.5 \%$ ) in eastern Sichuan basin. This high efficient hydrocarbon source kitchen basically reached over the dead line of the oil generation between late Indosinian epoch and early Yanshannia epoch. The oil formed in Late Triassic - early Jurassic migrated upward and charged to the upper Middle Carboniferous carbonate reservoir to produce the Carboniferous ancient oil reservoir. Due to the increasing burial depth, the ancient oil reservoirs experienced crude oil cracking in the early Himalayan movement and turned into gas source kitchen. The gases generated from the cracking of crude oil were stored in the existing Carboniferous reservoirs to form large Carboniferous gas reservoirs.

\section{Acknowledgements}

In this paper, this research was sponsored by the Natural Science Foundation of Shaanxi Province (Project No. 2013JM5006).

\section{References}

[1] Behar F., Ungerer P., Kressmann S., et al., Thermal evolution of crude oils in sedimentary basins, experimental simulation in a confined system and kinetic modeling. Revue de l'Institut Francais du Petrole., Vol. 46 (1991), p. 151-183.

[2] Braun R. L., Burnham A K., A nalysis of chemical reaction kinetics using a distribution of activation energies and simp lermodels. Energy and Fuels, 1(1987), p. 153.

[3] Burnham A.K., Gregg, H.R., Ward, R.L., et al.. Decomposition kinetics and mechanism of n-hexadecane-1,2-13C2 and dodece-1-ene-1,2-13C2 doped in petroleum and n-hexadecane. Geochimica et Cosmochimica Acta, Vol. 61(1997), p. 3725-3737.

[4] Cramer B, Faber E, Gerling P, et al., Reaction kinetics of stable carbon isotopes in natural gas-insights from dry, open system pyrolysis experiments. Energy \& Fuels, Vol. 15(2001),517-532.

[5] Domine F., Kinetics of hexane pyrolysis at very high pressures. 1. Experimental study. Energy and Fuels, Vol. 3(1989), p. 89-96.

[6] Horsfield B., Schenk H.J., Mills, N., et al., An investigation of the in-reservoir conversion of oil to gas, compositional and kinetic findings from closed-system pro-grammed-temperature pyrolysis. Organic Geochemistry, Vol. 19(1992),191-204.

[7] Ungerer P., Behar, F., Villalba, M., et al., Kinetic modelling of oil cracking. Organic Geochemistry, Vol. 13(1988), 857-868. 